\title{
Cytotoxicity Analysis of Ti-7.5Mo Alloy After Biomimetic Surface Treatment to Use as Dental Materials
}

\author{
Ana Lúcia do Amaral Escada ${ }^{\star}$, Samira Esteves Afonso Camargo ${ }^{b}$, Luana Marotta Reis de
}

Vasconcellos $^{b}$, Noala Vicensoto Moreira Milhan ${ }^{c}$, Ana Paula Rosifini Alves Claro ${ }^{a}$

\author{
${ }^{a}$ Departamento de Materiais e Tecnologia, Universidade Estadual Paulista - UNESP, Av. Dr. Ariberto \\ Pereira da Cunha, 333, Pedregulho, CEP 12.516-410, Guaratinguetá, SP, Brazil. \\ ${ }^{b}$ Departamento de Biociências e Diagnóstico Bucal, Universidade Estadual Paulista - UNESP, São José \\ dos Campos, SP, Brazil. \\ ${ }^{c}$ Universidade Estadual Paulista - UNESP, São José dos Campos, SP, Brazil.
}

\author{
Received: March 31, 2016; Revised: January 17, 2017; Accepted: August 01, 2017
}

\begin{abstract}
Titanium (Ti) and its alloys are widely used for medical and dental fields due to their excellent biocompatibility, high corrosion resistance, high specific strength and excellent mechanical properties. Different methods have been developed to improve the surface properties of titanium-based implant materials, and consequently the bone-bonding ability. The Ti-7.5Mo alloy was activated by an alkaline treatment with $5 \mathrm{M} \mathrm{NaOH}$, heat treatment and subsequent immersion in $\mathrm{SBFx} 5$ to investigate the in vitro response of osteoblastic-like cells (MG-63) on altered biomimetic surfaces. Sample surfaces were characterized by scanning electron microscopy. Cytotoxicity was assessed by the MTT assay, total protein content, alkaline phosphatase activity (ALP) and mineralized bone-like nodule formation. It was shown the que alkali treatment led to the formation of sodium titanate and immersion in SBFx 5 formed a film of calcium phosphate. The alkaline treatment and heat treatment of 7.5 Ti-Mo alloys followed by soaking them in SBFx 5 for 24 hours is a suitable technique once the final samples were biocompatible, allowed the attachment of the osteoblastic-like cells (MG-G3), and increased the mineralized like-bone nodules formation by these cells.
\end{abstract}

Keywords: titanium alloys, biomimetic treatment, cytotoxicity.

\section{Introduction}

Titanium (Ti) and its alloys are widely used in the medical and dental fields due to their excellent biocompatibility, high corrosion resistance, high specific strength and excellent mechanical properties ${ }^{1}$. The Ti-7.5Mo alloy is a biocompatible alloy, which has a low elastic modulus (55 GPa) and a high strength/modulus ratio. Thus, it is a potential candidate for orthopedic applications ${ }^{2,3}$. Despite these appropriate properties, titanium and its alloys are considered bioinert ${ }^{4}$.

Different methods have been developed to improve the surface properties of titanium-based implant materials, and consequently the bone-bonding ability. Through the surface treatment, it is possible to change the chemical composition, morphology, topography and roughness. Among the surface treatments, titanium plasma-spraying, acid-etching, gritblasting, anodization and calcium phosphate coatings ${ }^{5}$ are the most common.

Metal implants have been coated with layers of calcium phosphates mostly composed of hydroxyapatite to enhance hard tissue integration. Different methods have been used to coat metal implants, such as the sol-gel coating, sputterdeposition, plasma-spraying, electrophoretic deposition and biomimetic precipitation. The plasma-spraying coating method

\footnotetext{
*e-mail: analuciaescada@uol.com.br
}

is the only one that has been used in clinical practice; however, it has disadvantages ${ }^{5}$ including changes in crystal structure, phase composition, specific surface area and morphology ${ }^{6}$.

In order to avoid the limitations of plasma-sprayed HA coatings, a new coating method which is based on the natural process of biomineralization has been developed. This method, also called biomimetic method, comprises the precipitation of calcium phosphate apatite crystals onto the titanium surface, after contact with simulated body fluid (SBF), forming a coating ${ }^{7,8}$.

In this work, the influence of alkaline treatment and heat treatment on the formation of calcium phosphate layer on the surface of a Ti-7.5Mo alloy, after soaking in simulated body fluid (SBFx5) for 24 hours, was evaluated concerning the biological behavior of osteoblastic-like cells (MG-63) after contact with these samples.

\section{Materials and Methods}

\subsection{Samples}

The Ti-7.5Mo alloy was produced from sheets of commercially pure titanium $(99.9 \%)$ and molybdenum $(99.9 \%)$. Samples were melted in an arc furnace under an 
argon atmosphere. They were cold worked by swaging and bars with $10 \mathrm{~mm}$ of diameter were produced. Then discs with $4 \mathrm{~mm}$ of thickness were cut, sanded and samples were divided into three groups: Group 1 (G1): Ti-7.5Mo alloy, control; Group 2 (G2): alkaline treatment and heat treatment; and Group 3 (G3): Ti-7,5Mo alloy with alkaline treatment and heat treatment + immersion in SBFx 5 .

For alkaline surface treatment, samples were immersed in a $5.0 \mathrm{M} \mathrm{NaOH}$ aqueous solution at $80^{\circ} \mathrm{C}$ for 72 hours, washed with distilled water, and dried at $40^{\circ} \mathrm{C}$ for $24 \mathrm{~h}$ using a methodology proposed by Wei et al. $2002^{9}$. After alkaline treatment, samples were heat-treated at $450^{\circ} \mathrm{C}$ for $1 \mathrm{~h}$ in air in an electric furnace.

For SBF treatment Ti-7.5Mo discs were immersed into a polypropylene tube with SBF (Simulated Body Fluid) proposed by Barrère et al. $2002^{10}$ for 1 day at $36.5^{\circ} \mathrm{C}$ to form an calcium phosphate layer on the sample surface.

This SBF solution was prepared by dissolving reagent $\mathrm{NaCl}, \mathrm{MgCl}_{2} .6 \mathrm{H}_{2} \mathrm{O}, \mathrm{CaCl}_{2} \cdot 2 \mathrm{H}_{2} \mathrm{O}, \mathrm{Na}_{2} \mathrm{HPO}_{4}$, and $\mathrm{NaHCO}_{3}$ in distilled water under constant bubbling of carbon dioxide gas at $36.5^{\circ} \mathrm{C}$.

The sample surfaces were examined using a scanning electron microscope (SEM, LEO 1450 VP, Zeiss, Germany).

Contact angle study and surface energy were performed using an automated Goniometer (Ramé-Hard Instrument Co. - Advanced Goniometer model $n{ }^{\circ}$ 300-F1, Serial No. 709262). The equipment has a camera, which captures the image of the drop being deposited on the sample, through a device similar to an eyedropper. The profile of this drop is determined by a computer program that calculates the contact angle of the surfaces. For the superficial energy, the ethyleneglycol was used as the second liquid. For these analyzes an arithmetic mean of 3 trials was done.

\subsection{Cell culture experiments and analysis}

In this study, an established lineage of osteoblast-like cells (MG 63) was obtained from the Rio de Janeiro Cell Bank (Rio de Janeiro, RJ, Brazil). Cells were cultured in Modified Eagle's Medium (Gibco-Life Technologies, NY, USA) containing $10 \%$ fetal bovine serum (Gibco), $100 \mathrm{mg} /$ $\mathrm{mL}$ streptomycin (Gibco) and $100 \mathrm{U} / \mathrm{mL}$ penicillin (Gibco) at $37^{\circ} \mathrm{C}$ in a humidified atmosphere of $5 \%(\mathrm{v} / \mathrm{v}) \mathrm{CO}_{2}$. The cell culture medium was changed every two days and cell growth was assessed using a reverse phase microscope (Model Axiovert 40C, Carl Zeiss Microscopy GmbH, Jena, Germany).

Initially, all the samples were placed into well plates and were sterilized in absolute ethanol (100\%) and then UV-exposed for 3 hours. Next, $2 \times 10^{4}$ cells were placed in contact with the samples (G1, G2 and G3), for in vitro analysis. Seven wells were used for each material in three independent experiments. All in vitro procedures were performed according to ISO 10993 guidelines.

\subsection{SEM evaluation}

The cell attachment and the morphology of the cells were investigated using SEM (Inspect S50, FEI Company, Brno, Tcheca Republik) after 3 days of MG-63 cells growth on the samples. The supernatant was removed and the samples were rinsed twice with PBS. The adhered cells in samples were fixed with 4\% glutaraldehyde in PBS, dehydrated using a series of ascending ethanol concentrations $(70 \%$, $80 \%, 90 \%$ and $100 \%$ at 20 mins each), air-dried at room temperature for $24 \mathrm{~h}$.

For SEM analysis, the samples were sputter-coated with palladium-gold alloy (Polaron SC 7620 Sputter Coater, Quorum Technologies, Newhaven, UK) at a thickness of 7-10 nm (10-15 mA, under a vacuum of $130 \mathrm{mTorr})$. The SEM was operated between 15 and $30 \mathrm{kV}$, spot 3 to 6 .

\subsection{Citotoxicity assay}

The cells were maintained in DMEM supplemented with $10 \% \mathrm{PBS}$, penicillin (100 U/ ml) and streptomycin $(100 \mathrm{mg} /$ $\mathrm{mL}$ ) at $37^{\circ} \mathrm{C}$ for 24 hours in a humidified atmosphere with 5 $\% \mathrm{CO}_{2}$. After this period, the old medium was removed and the cell cultures were exposed to the samples (G1, G2 and G3) and maintained in the incubator for 3, 7 and 14 days. Next, the number of living cells was determined by MTT assay (3-(4,5 dimethylthiazol-2-yl)-2,5-diphenyltetrazolium bromide, Sigma, St Louis, MO, USA). The activity was quantified by dissolution of MTT in $0.1 \mathrm{~N} \mathrm{NaOH}(6.25$ $\mathrm{v} / \mathrm{v} \%$ ) in DMSO (dimethyl sulfoxide) and then the reading of optical density of the resulting solution was measured by spectrophotometer (Biotek - EL808IU) at $570 \mathrm{~nm}$. The cytotoxicity was expressed in percentage relative to the control group (only cells) $(100 \%)$.

\subsection{Total protein content}

To assess the total protein content, the cells were plated on the samples into 24-well plates at a density of 20,000 cells/ well for 3, 7 and 14 days. After these periods, the old medium was removed, the wells were washed three times with PBS at $37^{\circ} \mathrm{C}$ and filled with $2 \mathrm{~mL}$ of $0.1 \%$ sodium lauryl sulfate (Sigma) according to the modified Lowry method (Lowry, et al. 1951). After $30 \mathrm{~min}, 1 \mathrm{~mL}$ of this solution from each well was mixed with $1 \mathrm{~mL}$ of Lowry solution (Sigma) and left for $20 \mathrm{~min}$ at room temperature. Next, $0.5 \mathrm{~mL}$ of the solution of Folin-Ciocalteau phenol reagent (Sigma) was added for $30 \mathrm{~min}$ at room temperature. Absorbance was measured at $680 \mathrm{~nm}$ using a UV 1203 spectrophotometer (Shimadzu Europa GmbH, Duisburg, Germany). The total protein content was calculated based on an albumin standard curve and expressed in $\mu \mathrm{g} / \mathrm{mL}$.

\subsection{Alkaline phosphatase activity (ALP)}

The same lysates described above were used to determine ALP activity through the releasing of thymolphthalein 
monophosphate, using a commercial Kit (Labtest Diagnóstica, Belo Horizonte, BR) according to the manufacturer's instructions. Initially, the cells were lysated with $2 \mathrm{~mL}$ of $0.1 \%$ sodium lauryl sulfate (Sigma). Then, $50 \mu \mathrm{L}$ of thymolphthalein monophosphate were mixed with $0.5 \mathrm{~mL}$ of $0.3 \mathrm{M}$ diethanolamine buffer for $2 \mathrm{~min}$ at $37^{\circ} \mathrm{C}$. After that, $50 \mu \mathrm{L}$ of the lysates obtained from each well was added for $10 \mathrm{~min}$ at $37^{\circ} \mathrm{C}$. Also, $2 \mathrm{~mL}$ of $0.09 \mathrm{M} \mathrm{Na}_{2} \mathrm{CO}_{3}$ and $0.25 \mathrm{M} \mathrm{NaOH}$ were added for color development. The absorbance was measured by spectrophotometer (Shimadzu Europa GmbH UV 1203) at $590 \mathrm{~nm}$ and the obtained data were shown as alkaline phosphatase activity normalized by total protein content. The values were presented in $\mu \mathrm{mol}$ of thymolphthalein $/ \mathrm{h} / \mathrm{mg}$ protein $/ \mathrm{mL}$.

\subsection{Mineralized bone-like nodule formation}

For quantitative analysis of mineralized matrix nodules, the cells were plated on the samples into 24-well plates at a density of 20,000 cells/well and kept in an incubator for 21 days. Then, the samples were washed three times with Hank's solution (Sigma) at $37^{\circ} \mathrm{C}$, and the cultures were fixed with $70 \%$ ethanol for 1 hour at $4^{\circ} \mathrm{C}$. Following fixation, the samples were washed twice with PBS and stained with $2 \%$ Alizarin red (Sigma), $\mathrm{pH} 4.2$, for 15 minutes at $37^{\circ} \mathrm{C}$. This solution is known for staining nodules of mineralized matrix. The samples were washed three times with deionized $\mathrm{H}_{2} \mathrm{O}$ and left to dry for $24 \mathrm{~h}$ at $37^{\circ} \mathrm{C}$. The quantification of mineralized formation was performed according to the method previously described by Gregory et al. (Gregory, et al. 2004). Next, $560 \mu \mathrm{L}$ of $10 \%$ acetic acid was added to each well, followed by $40 \mu \mathrm{L}$ of $10 \%$ ammonia hydroxide in order to neutralize the acid. The absorbance was measured by spectrophotometer (Biotek - EL808IU) at $405 \mathrm{~nm}$. The values were expressed in optical density.

\subsection{Statistical analysis}

ALP activity, total protein content, citotoxicity assay and nodules formation are expressed as mean \pm standard deviations. Statistical analyses were performed using GraphPad Prism software (GraphPad Software version 5.0, San Diego, CA, USA). Statistical comparisons were carried out via ANOVA one-way, followed by a multiple comparison Tukey test where applicable. Differences were considered statistically significant at $\mathrm{p}<0.05$. The results are representative of experiments performed with three distinct primary cultures.

\section{Results}

Figure 1a shows the image obtained in the scanning electron microscope of sample sanded control where it is possible to view the $\mathrm{TiO}_{2}$ passive layer formed on the of Ti-7.5Mo alloy surface. During immersion in $5 \mathrm{M}$ $\mathrm{NaOH}$ for 72 hours, the metal $\mathrm{O}$ passive layer dissolves
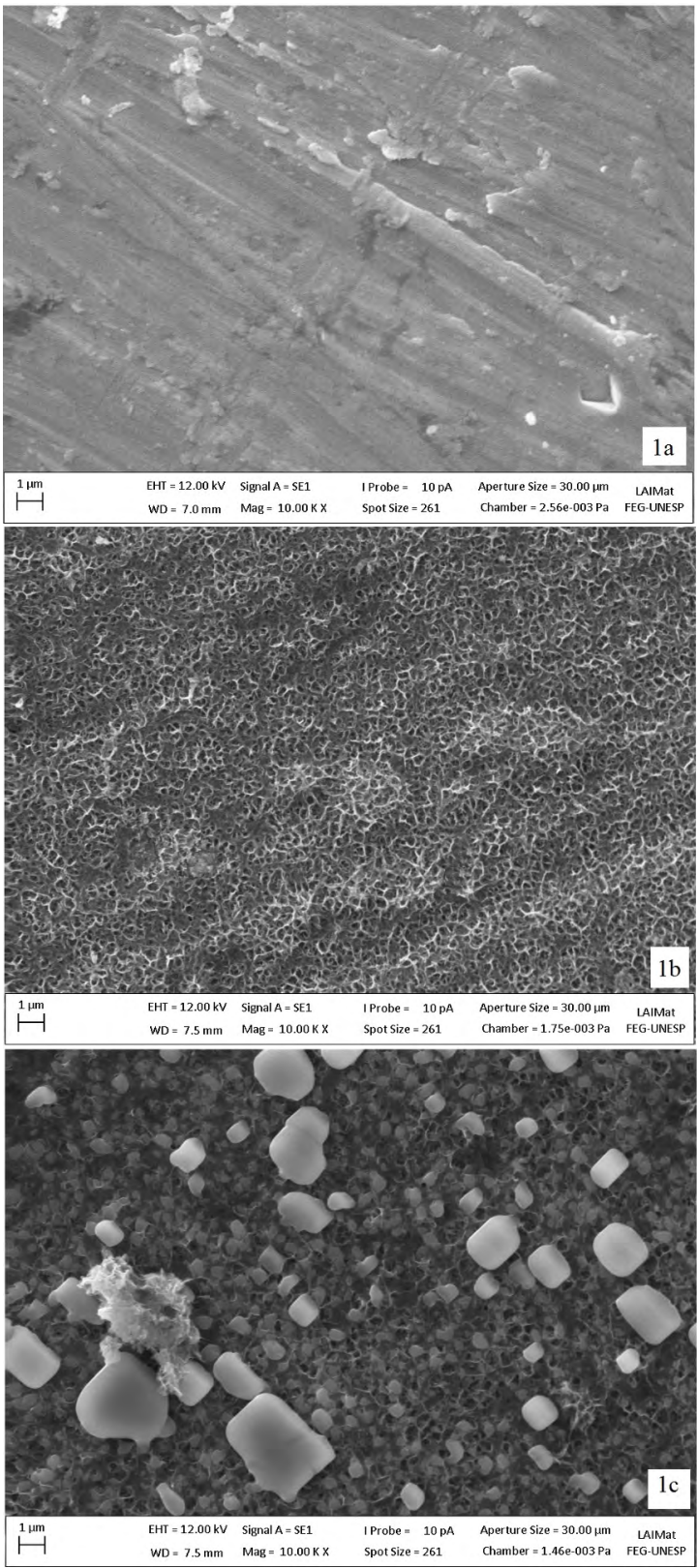

Figure 1. SEM micrographs of the Ti-7.5Mo alloy: Group 1 (G1) sample control (1a); Group 2 (G2): $\mathrm{NaOH}$ alkaline treatment and heat treatment (1b); and Group 3 (G3): Ti-7.5Mo alloy with alkaline treatment and heat treatment + immersion in $\mathrm{SBFx} 5$ (1c)

to form metal-OH and a porous film of sodium titanate is formed (Figure 1b). When this layer is exposed to $\mathrm{SBF}$, the titanium coating formed by chemical treatment releases $\mathrm{Na}^{+}$ions of the sodium titanate layer in exchange for $\mathrm{H}_{3} \mathrm{O}^{+}$ions, wich increases the $\mathrm{pH}$ of the solution and promotes the nucleation process of some phosphates. The Ti-OH groups negatively charged react with $\mathrm{Ca}_{2}^{+}$ions fluid forming amorphous calcium titanate, that reacted with phosphorus ions to form the calcium phosphate layer (Figure 1c). 
The hydrophilic potential is a very important parameter for biomaterials. Contact angle studies were performed to evaluate this hydrophilic potential provided by various surface coatings (Table 1). The results show that the contact angle of the samples decreased from $89.84^{\circ}(\mathrm{G} 1)$ to $77.33^{\circ}$ (G2) and $51.84^{\circ}(\mathrm{G} 3)$ when this study was carried out with deionized water. In the study made with ethyleneglycol, the contact angle decreased from $77.55^{\circ}$ (G1) to $48.58^{\circ}(\mathrm{G} 2)$ and $35.55^{\circ}(\mathrm{G} 3)$. These results were used to calculate the surface energy that increased from $40.22^{\circ}(\mathrm{G} 1)$ to $50.31^{\circ}$ (G2) and $63.12^{\circ}(\mathrm{G} 3)$.

Table 1. Contac angle values and surface energy

\begin{tabular}{cccc}
\hline Samples & Water & $\begin{array}{c}\text { Ethylene } \\
\text { glycol }\end{array}$ & Surface energy \\
\hline G1 & $89,84 \pm 0.26$ & $77.55 \pm 1.48$ & $40.22 \pm 0.20$ \\
G2 & $77.33 \pm 0.79$ & $48.58 \pm 1.01$ & $50.31 \pm 0.38$ \\
G3 & $51,84 \pm 0.32$ & $35.55 \pm 1.48$ & $63.12 \pm 0.23$ \\
\hline
\end{tabular}

\subsection{SEM evalution}

The cell attachment was observed in all groups. There was an intimate contact between the cells and all the surfaces. The cells were extended and spread on the samples. The SEM images showed that the groups G1 and G2 presented higher number of cells than G3 group (Figure 1).

\subsection{Citotoxicity assay}

Statistical analysis of the data obtained in the MTT test showed that none of the tested materials was cytotoxic after 3,7 or 14 days of contact with the cells. The groups G1, G2 and $\mathrm{G} 3$ showed no values of absorbance statistically different from the control group ( $>>0.05$ ). Moreover, the groups G1 and G3 showed absorbance values higher than $100 \%$ on the $3^{\text {th }}$ and $14^{\text {th }}$ day (Figure 2).

\subsection{Total protein content}

The values of total protein content were similar among the groups in all experimental periods ( $\mathrm{p}>0.05$ ) (Figure 3 ). In all groups, the production of total protein on the $3^{\text {th }}$ day was lower than this production on the $7^{\text {th }}$ day, which was lower than this production on the $14^{\text {th }}$ day.

\subsection{Alkaline phosphatase activity (ALP)}

The values of ALP on the $3^{\text {th }}$ and $14^{\text {th }}$ days showed no statistically significant difference among the groups. On the other hand, on the $7^{\text {th }}$ day a difference $(\mathrm{p}<0.05)$ was observed between G1 and G3 groups, with G3 presenting a higher value of ALP than G1 group (Figure 4).

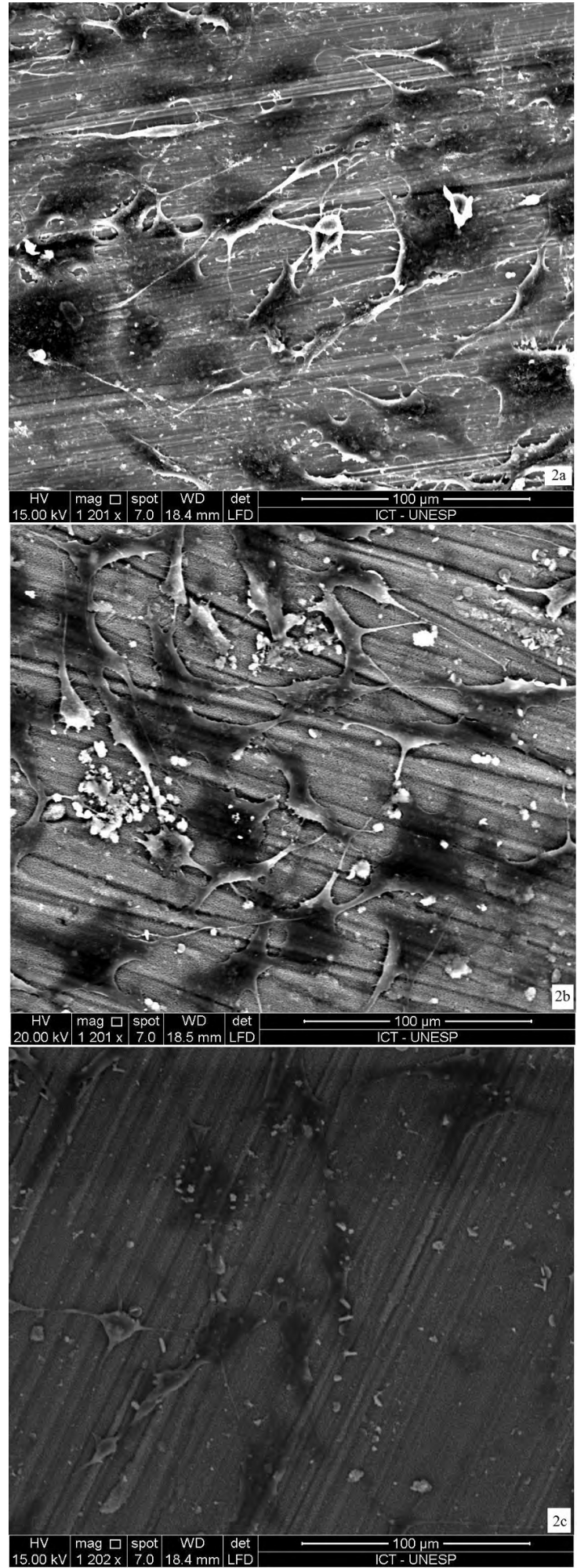

Figure 2. Cell attachment on the samples at 3 days, as observed by SEM (A) G1, (B) G2, and (C) G3 

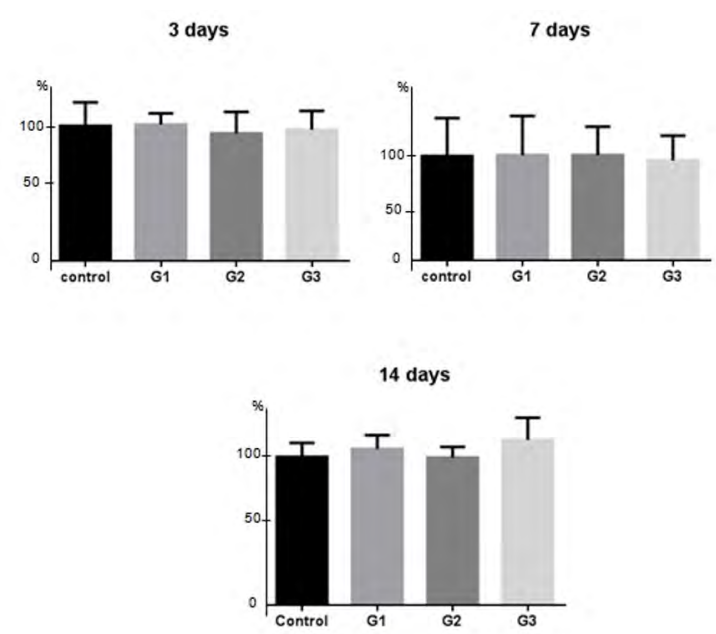

Figure 3. Graph showing the mean percentage of absorbance, obtained with MTT assay, of G1, G2 and G3 and control group $(100 \%)$ after 3,7 and 14 days

\subsection{Mineralized bone-like nodule formation}

The data obtained in this test showed that all groups allowed the mineralization of extracellular matrix after 21 days of osteoblast-like culture in contact with the samples.
Statistical analysis of these data showed that G3 group presented the highest formations mineralized bone-like nodules. A statistical difference was observed between this group and the other groups $(\mathrm{p}<0.05)$ (Figure 5). In addition, there was not a significant difference between G1 and G2 groups ( $p>0.05$ ).

\section{Discussion}

The biomimetic method uses supersaturated aqueous solutions with ionic composition resembling the human plasma. This process allows coating of metal implants with apatite crystals ${ }^{4,7,8}$. It is believed that biomimetic calcium phosphate (Ca-P) coatings enhances the bone integration as compared to the noncoated implants ${ }^{7}$.

Aiming to accelerate the deposition of coatings through aqueous solutions, some methods have been developed ${ }^{5}$. Kokubo et al. demonstrated that alkaline-treated titanium without heat treatment form apatite after soaking in $\mathrm{SBF}^{11}$. However, a study evaluating the bone-bonding ability of pure titanium with alkaline and heat treatment showed that both treatments are essential for preparing bioactive titanium, once the alkaline-treated titanium without heat treatment had no bone-bonding ability because of the unstable reactive surface layer of alkaline-treated titanium ${ }^{12}$.

\section{Total Protein}
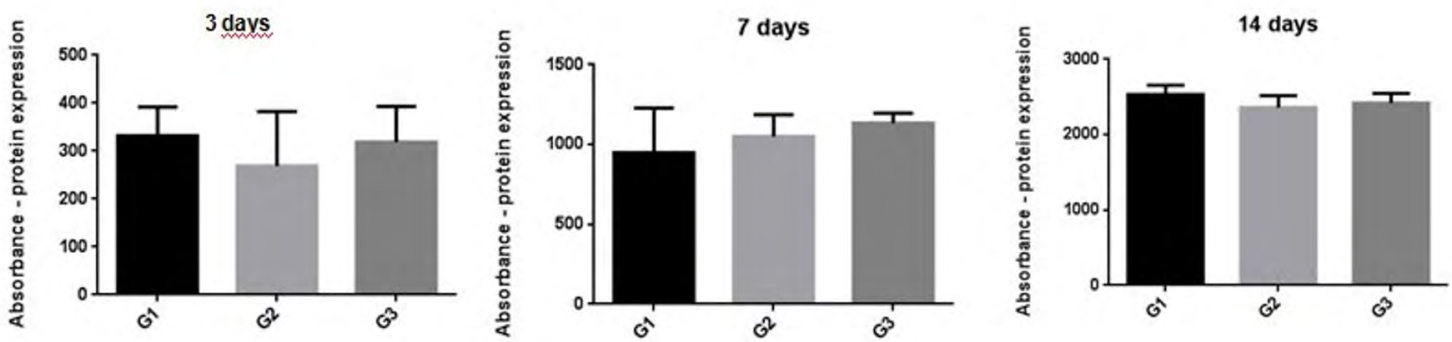

Figure 4. Total protein content after 3, 7 and 14 days of cell culture on the samples. The values are reported as mean $\pm \operatorname{SD}(n=3)$

\section{ALP Activity}

3 days

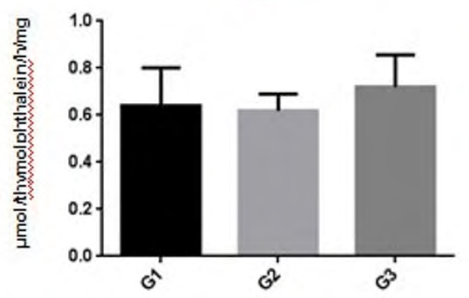

7 days

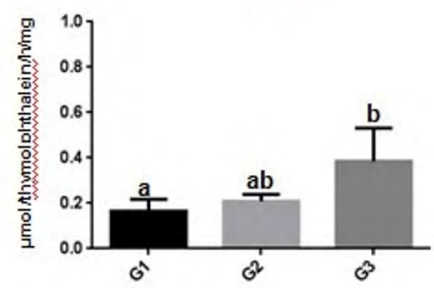

14 days

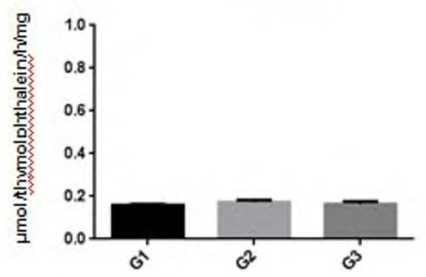

Figure 5. ALP activity after 3, 7 and 14 days of cell culture on the samples. The values are reported as mean \pm SD. a,b represent Tukey test results where the groups presenting different superscript letters differ statistically 
Moreover, biomimetic Ca-P coatings on Ti6Al4V alloy using simulated body fluids five-fold concentrated (SBFx5) were performed with good results ${ }^{10}$. In this study, samples were submitted to the alkaline treatment and heat treatment to provide the formation of calcium phosphate layer on the surface of a Ti-7.5Mo alloy, after soaking in simulated body fluid (SBFx5) for 24 hours. Thus, osteoblastic-like cells (MG-63) were evaluated regarding the biological responses after contact with theses samples.

The biomimetic methods have been proposed as they have some advantages when compared to the others ${ }^{10}$. Chen et al. $(2003)^{13}$ reported that a microporous surface benefits the formation of calcium phosphate nuclei, and improves the adhesion between the porous coating and the substrate, and the authors found the presence of pores with a diameter between 1-2 $\mu \mathrm{m}$. According to Citeau et al. (2005) $)^{14}$ surface roughness is one of the essential factors for osseointegration of dental and orthopedic implants. It increases the mechanical anchoring of calcium phosphate which acts as a support for colonization and adherence of osteogenic cells.

The hydrophilic potential is a very important parameter for biomaterials. Contact angle studies were performed to evaluate this hydrophilic potential provided by various surface coatings. After alkaline treatment (G2) and immersion in SBFX5 (G3), a significant decrease in the contact angle was observed; however, an increase in surface energy was obtained, which improved the hydrophilic potential of this condition. The biomaterials surface energy is one of the most important surface properties (such as morphology and chemical composition), determining interactions between the biomaterials and the surrounding biological environment ${ }^{15}$. As the relationship between the contact angle and the surface energy occurs inversely on the same surface, a decrease of this angle increases the wettability of the surface ${ }^{3}$, showing that the study presented coherence in its results.

The wettability of the implant surface (hydrophobic or hydrophilic) has a profound influence on the cells behavior during the osseointegration process, which begins when the implant is in contact with the blood. According to Elias et al., $(2008)^{16}$ the adsorption and adhesion behavior of proteins on the surface of an implant depends on its surface properties of the implant. On hydrophobic surfaces, traces of antibodies reduce cell adsorption. In hydrophilic surfaces, traces of thrombin and prothrombin predominate and increase the cellular adsorption. Therefore, in order to promote the proliferation of human osteoblasts, it is necessary to increase the surface area of the implant, which consequently increases the wettability of the surface. This increased wettability results in increased cell proliferation, indicating the importance of hydrophilicity for applications such as dental implants. In addition, the increase in surface energy can be attributed to the increase of the surface area caused by the calcium phosphate coating ${ }^{17}$.
The biocompatibility of materials is related to cell behavior in contact with the materials ${ }^{18}$. Cell attachment is presumably the most important stage of the cell interaction with a biomaterial because the cell behavior depends on signaling cascades initiated via adhesion ${ }^{19}$ needed for other cellular activities, such as spreading, proliferation and biosynthesis. After initial attachment, the cells become flattened and finally fully spread ${ }^{20}$.

The surface of the porous Ti-7.5Mo allow the attachment of cells, and the rough surfaces seems to be more favorable for cell growth ${ }^{21}$. A previous study indicated that cell adhesion influences the process of cell proliferation ${ }^{22}$. In this study, the qualitative analysis of SEM images showed that the treatment did not impair the attachment of the cells, which were extended and spread on all the samples. Although fewer cells have been observed on the samples of G3 group, the number of viable cells in contact with these samples was similar to the control group. The explanation for this finding may be related to the type of analysis performed in both tests. The cell attachment by MEV was evaluated just in some areas of the samples, in order to prove the cell attachment and spreading, which was observed in all groups. On the other hand, the number of viable cells was determined by a quantitative test. In addition, the tests related to osteogenesis indicated that osteoblast differentiation was enhanced in G3 group, which suggests that the attachment was appropriate and allowed the differentiation of the cells, especially in this group.

The cell viability was measured by citotoxicity assay, after contact with the samples, through MTT assay. This assay shows not only the number of cells, but also the level of its metabolic activity because it is based on the activity of enzymes, such as succicil dehydrogenase, which is present in viable cells ${ }^{23}$. A previous study which evaluated Ti-7.5Mo alloys showed that these alloys did not induce cell death, when the cells were plated on the samples or incubated for 24-72 $\mathrm{h}^{3}$. In our study, G3 group showed absorbance values higher than $100 \%$ on the $3^{\text {th }}$ and $14^{\text {th }}$ days, as occurred in G1. In this way, we noticed that independently of the treatment, the alloys were not cytotoxic for the cells, after 3, 7 and 14 days of contact with them.

Tests evaluating the total protein content, ALP and mineralized bone-like nodule (Figure 6) formation were performed in this study. These tests have been used in many in vitro studies in order to analyze the behavior of bone cells in contact with biomaterials, concerning the indicator of osteogenesis ${ }^{24,25,26,27}$.

The total protein content is associated with the capacity of synthesis of the cells. It is known that it is an important parameter to estimate the osteogenesis in vitro, and this method has been used for this purpose ${ }^{24,25,26}$. In this study, the values of total protein content were similar between treated and untreated groups. It was observed that this process was 


\section{Mineralized bone-like nodule formation ( 21 days)}

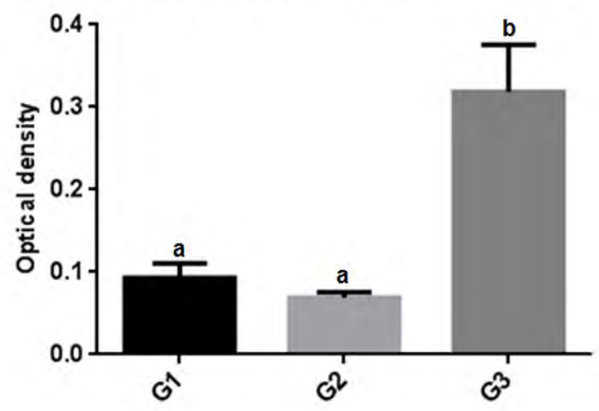

Figure 6. Mineralized like-bone nodules formation after 21 days of cell cell culture on the samples. Values are reported as mean \pm SD. ${ }^{\mathrm{a}, \mathrm{b}}$ represent tukey test results where the groups presenting different superscript letters differ statistically

influenced by the period of osteoblast-like culture in contact with the samples, with the highest values of total protein content occurring on the $14^{\text {th }}$ day. Similarly, a previous study also demonstrated that the total protein content increases from $3^{\text {th }}$ to $14^{\text {th }}$ day ${ }^{25}$, result that corroborates with ours and indicates that in a suitable environment the ability of cells to synthesize proteins increases in the course of time.

Among all the proteins synthesized by the cells, alkaline phosphatase is an important one. Its production characterizes a functional parameter that reflects the ability of cell differentiation in vitro, representing an important indicator of osteoblast differentiation ${ }^{27}$. It was previously demonstrated that the surface topography of hydroxyapatite did not cause alteration in the total protein content while the ALP is affected by it, as observed in our study, in which just the ALP was enhanced in G3 group ${ }^{28}$.

Correlation between ALP and mineralized matrix production by osteoblasts has been observed ${ }^{24,26,29}$. A previous study demonstrated that enzimatic activity of alkaline phosphatase is necessary to form mineralized tissue ${ }^{29}$, findings that are in accordance with ours, since there was higher ALP on the $7^{\text {th }}$ day in G3 group, which also demonstrated higher formation of mineralized like-bone nodules. In this way, the level of ALP activity necessary to produce mineralized like-bone nodules formation was reached in all the groups, especially in the group with biomimetic treatment.

In studies using osteogenic cultures, the mineralization is considered a final stage of the cell differentiation (Hoemann et al., 2009). Previous reports have demonstrated, through alizarin test, that bone-like formations enhances after different treatments ${ }^{24,26,30}$. In addition, the formation of mineralized nodules is influenced not only by the material composition but also by the surface topography ${ }^{26}$. In this work, G3 group interestingly provided a more suitable environment for bone-like tissue formation. Therefore, our results indicate that biomimetic method on the Ti-7.5Mo alloy may enlarge the formation of mineralized like-bone nodules. It probably occurs due to calcium phosphate coatings, which in a previous in vivo study demonstrated an early bone apposition on the BCA-coated dense Ti6Al4V and porous Ta cylinders ${ }^{7}$.

Previously, an in vivo study showed that Ti-7.5Mo alloy improve the bone formation in rabbit femur compared to Ti-6Al-4V alloy. According to these authors, this facilitation of bone formation could be associated with the positive properties of this alloy, such as the low modulus and good biocompatibility ${ }^{3}$. Our in vitro results suggest that these good properties of Ti-7.5Mo alloy can be further improved with biomimetic calcium phosphate coatings.

\section{Conclusion}

The alkali treatment enables to obtain a sodium titanate porous film. The immersion in SBFx 5 enables the formation of a calcium phosphate layer that has a bioactive surface. The alkaline treatment and heat treatment of Ti-7.5Mo alloys followed by soaking them in SBFx 5 for 24 hours is a suitable technique once the final samples were biocompatible, allowed the attachment of the osteoblastic-like cells (MG-63), and increased the mineralized like-bone nodules formation by these cells.

\section{Acknowledgments}

The authors acknowledge financial support received from FAPESP (Project 2013/08200-9) and CNPq 486352/2013-7.

Laboratório de Imagens de Materiais - LAIMat, UNESP - Guaratinguetá. Laboratório de Estudos Interdisciplinar de Células - LEIC - ICT/UNESP. São José dos Campos.

\section{References}

1. Niinomi M. Recent metallic materials for biomedical applications. Metallurgical and Materials Transactions A. 2002;33:477-486.

2. Lin CW, Ju CP, Lin JHC. A comparison of the fatigue behavior of cast Ti-7.5Mo with c.p. titanium, Ti-6Al-4V and Ti-13Nb13Zr alloys. Biomaterials. 2005;26(16):2899-2907.

3. Lin DJ, Chuang CC, Lin JHC, Lee JW, Ju CP, Yin HS. Bone formation at the surface of low modulus Ti-7.5Mo implants in rabbit femur. Biomaterials. 2007;28(16):2582-2589.

4. Nebe JB, Müller L, Lüthen F, Ewald A, Bergemann C, Conforto $\mathrm{E}$, et al. Osteoblast response to biomimetically altered titanium surfaces. Acta Biomaterialia. 2008;4(6):1985-1995.

5. Le Guéhennec L, Soueidan A, Layrolle P, Amouriq Y. Surface treatments of titanium dental implants for rapid osseointegration. Dental Materials. 2007;23(7):844-854.

6. Radin SR, Ducheyne P. Plasma spraying induced changes of calcium phosphate ceramic characteristics and the effect on in vitro stability. Journal of Materials Science: Materials in Medicine. 1992;3(1):33-42.

7. Barrère F, van der Valk CM, Meijer G, Dalmeijer RAJ, de Groot K, Layrolle P. Osteointegration of biomimetic apatite coating applied onto dense and porous metal implants in femurs of goats. Journal of Biomedical Materials Research Part B: Applied Biomaterials. 2003;67B(1):655-665. 
8. Escada AL, Machado JP, Schneider SG, Rezende MC, Claro AP. Biomimetic calcium phosphate coating on Ti-7.5Mo alloy for dental application. Journal of Materials Sciences: Materials in Medicine. 2011;22(11):2457-2465.

9. Wei M, Kim HM, Kokubo T, Evans JH. Optimising the bioactivity of alkaline-treated titanium alloy. Materials Science and Engineering: C. 2002;20(1-2):125-134.

10. Barrère $F$, van Blitterswijk CA, de Groot $K$, Layrolle P. Influence of ionic strength and carbonate on the Ca-P coating formation from SBFx5 solution. Biomaterials. 2002;23(9):1921-1930.

11. Kokubo T, Miyaji F, Kim HM, Nakamura T. Spontaneous Formation of Bonelike Apatite Layer on Chemically Treated Titanium Metals. Journal of the American Ceramic Society. 1996;79(4):1127-1129.

12. Nishiguchi S, Nakamura T, Kobayashi M, Kim HM, Miyaji F, Kokubo $\mathrm{T}$. The effect of heat treatment on bone-bonding ability of alkali-treated titanium. Biomaterials. 1999;20(5):491-500.

13. Chen MF, Yang XJ, Liu Y, Zhu SL, Cui ZD, Man HC. Study on the formation of an apatite layer on NiTi shape memory alloy using a chemical treatment method. Surface and Coatings Technology. 2003;173(2-3):229-234.

14. Citeau A, Guicheux J, Vinatier C, Layrolle P, Nguyen TP, Pilet $P$, et al. In vitro biological effects of titanium rough surface obtained by calcium phosphate grid blasting. Biomaterials. 2005;26(2):157-165.

15. Wang Z, Ou J, Wang Y, Xue M, Wang F, Pan B, et al. Antibacterial superhydrofobic silver on dicerses substrates based on the mussel-inspired polydopamine. Surface and Coantings Technology. 2015;280:378-383.

16. Elias CN, Lima JHC, Valiev R, Meyers MA. Biomedical applications of titanium and its alloys. Journal of The Minerals, Metals \& Materials Society. 2008;60(3):46-49.

17. Lynge ME, Schattling P, Städler B. Recent developments in poly(dopamine)-based coatings for biomedical applications. Nanomedicine (Lond). 2015;10(17):2725-2742.

18. Wilke A, Orth J, Lomb M, Fuhrmann R, Kienapfel H, Griss $\mathrm{P}$, et al. Biocompatibility analysis of different biomaterials in human bone marrow cell cultures. Journal of Biomedical Materials Research Part A. 1998;40(2):301-306.

19. Schlie S, Gruene M, Dittmar H, Chichkov BN. Dynamics of Cell Attachment: Adhesion Time and Force. Tissue Engineering Part C: Methods. 2012;18(9):688-696.
20. Khalili AA, Ahmad MR. A Review of Cell Adhesion Studies for Biomedical and Biological Applications. International Journal of Molecular Sciences. 2015;16(8):18149-18184.

21. Hsu HC, Hsu SK, Tsou HK, Wu SC, Lai TH, Ho WF. Fabrication and characterization of porous Ti-7.5Mo alloy scaffolds for biomedical applications. Journal of Materials Science: Materials in Medicine. 2013;24(3):645-657.

22. Sista S, Wen C, Hodgson PD, Pande G. The influence of surface energy of titanium-zirconium alloy on osteoblast cell functions in vitro. Journal of Biomedical Materials Research. Part A. 2011;97(1):27-36.

23. Mosmann T. Rapid colorimetric assay for cellular growth and survival: Application to proliferation and cytotoxicity assays. Journal of Immunological Methods. 1983;65(1-2):55-63.

24. Beloti MM, Martins W Jr, Xavier SP, Rosa AL. In vitro osteogenesis induced by cells derived from sites submitted to sinus grafting with anorganic bovine bone. Clinical Oral Implants Research. 2008;19(1):48-54.

25. Beloti MM, Rosa AL. Osteoblast differentiation of human bone marrow cells under continuous and discontinuous treatment with dexamethasone. Brazilian Dental Journal. 2005;16(2):156-161.

26. de Andrade DP, de Vasconcellos LM, Carvalho IC, Forte LF, de Souza Santos EL, Prado RF, et al. Titanium-35niobium alloy as a potential material for biomedical implants: In vitro study. Materials Science \& Engineering: C, Materials for Biological Applications. 2015;56:538-544.

27. Hoemann CD, El-Gabalawy H, McKee MD. In vitro osteogenesis assays: Influence of the primary cell source on alkaline phosphatase activity and mineralization. Pathologie Biologie. 2009;57(4):318-323.

28. Rosa AL, Beloti MM, Noort RV, Hatton PV, Devlin AJ. Surface topography of hydroxyapatite affects ROS17/2.8 cells response. Pesquisa Odontológica Brasileira. 2002;16(3):209-215.

29. Sugawara Y, Suzuki K, Koshikawa M, Ando M, Iida J. Necessity of enzymatic activity of alkaline phosphatase for mineralization of osteoblastic cells. Japanese Journal of Pharmacology. 2002;88(3):262-269.

30. Ni GX, Yao ZP, Huang GT, Liu WG, Lu WW. The effect of strontium incorporation in hydroxyapatite on osteoblasts in vitro. Journal of Materials Science: Materials in Medicine. 2011;22(4):961-967. 